\title{
The Willingness to Trade Privacy in the Context of WTA and WTP
}

\author{
Wojciech Bizon and Andrzej Poszewiecki
}

\begin{abstract}
The question of privacy attracts a growing interest not only among lawyers and politicians, but is also becoming the focus of attention for economists. However, private data are difficult to evaluate and no typical market for the turnover of such data exists yet. The individual valuation of privacy also poses major problems. The authors of the study have undertaken the task of assessing how and if valuations of such data differ depending on whether we want to protect or sell our data. Tests carried out by the authors lead to the conclusion that the readiness to protect information (measured as the percentage of respondents who do not decide to sell data) is higher than the economically equivalent and having the same effect (data protection) readiness to buy back data that have been shared before.
\end{abstract}

Index Terms-Privacy, WTA, WTP, economics of privacy.

\section{REASONS FOR ADRESSING THE SUBJECT}

The interest of economists in the question of privacy, which is generally interpreted as having control over or protecting personal data, is understandable. The protection and disclosure of personal data generate consequences with measurable economic effects. The transfer of modern economies to the stage of the intense production of knowledge and the very fast development of IT technologies in recent years (in particular, the birth and development of Internet) have increased the scope of information that can be collected, stored, analysed, and used substantially.

The topic of privacy is capturing more and more attention among the general public as well. However, it remains a subject that is difficult to analyse. This results, inter alia, from problems related to its definition. The situation stems from the fact that privacy has different meanings for individual people [1]. It is presented as the right to maintain one's personal space and the right to be alone [2]; as the possibility to control over and provide the security of personal data [3]; or as one of the aspects of human dignity, autonomy, and thus, one's freedom [4].

In the times when personal data can be easily transformed into a concrete, profiled (and thus more effective) offer, entrepreneurs are pressed for gaining such data. On the other hand, consumers are becoming more concerned with the fact

Manuscript received March 11, 2016; revised July 13, 2016. This study was funded by the National Science Centre (Poland), by the funds assigned on the base of decision number DEC-2012/07/D/HS4/02014.

The authors are with the University of Gdansk, ul. Armii Krajowej 119/121, 81-824 Sopot, Poland (e-mail: w.bizon@univ.gda.pl, poszewiecki@panda.bg.univ.gda.pl). that a third party has access to their data ${ }^{1}$. This refers to the problem (perceived as notorious) of presenting commercial offers and the question of hazard to safety (identity theft, hacking bank websites, etc.).

While the awareness of personal data and their commercial importance seems to be more and more common, what remains to be resolved is the question of dichotomy in perceiving the importance (value) of data that have been already revealed and data that might be disclosed in the future. It can be suspected that consumers value differently the same data that were revealed some time in the past and those that they might disclose at present.

The valuation of privacy has become an important and interesting problem in this area. According to the economic assumptions of rationality, a consumer values goods on a similar level, whether he is their owner or not. However, the empirical research have revealed inconsistencies in this respect and indicate the disproportion between the sale price limit (a minimum price for which a consumer is ready to sell one's goods - WTA) and the purchase price limit (a maximum price which a consumer is ready to pay for goods WTP). Such differences are often explained with the income effect, which fails, however, to clarify such differences in prices obtained in empirical research [5], [6]. An attempt to explain the WTA-WTP disparity phenomenon based on behavioural economy is the endowment effect proposed by $\mathrm{R}$. Thaler [7]. In essence, it means that consumers, ceteris paribus, prefer (value higher) things which they posses than those they could potentially purchase.

Empirical research into the valuation of privacy can be classified into two groups. The first larger group includes research that measure, either directly or indirectly, the amount or benefit that is considered sufficient by a client to provide one's personal data, i.e. the willingness to accept (WTA) or to give away one's data (for example: [8]-[13]) The second, smaller group of research, concerns the factual prices and intangible costs which clients are ready to pay (WTP willingness to pay) to protect their privacy [14]-[17].

Most research conducted so far constitute laboratory experiments. The obtained results have indicated a relatively low valuation of privacy. Tsai et al. [17] found out that participants of an experiment paid a small additional amount (about 50 cents) for purchases with better privacy protection. Varian et al. [15] and Png [16] verified what amount American consumers were ready to spend on protection

\footnotetext{
${ }^{1}$ However, one could quote some research (Varian 1996, G. Calzolari and A. Pavan, 2006, Lenard and Rubin, 2009; Goldfarb and Tucker, 2010) that indicate the benefits obtained by consumers due to the greater availability of their private data, e.g. better suited offers, lower expenditures on marketing by enterprises and, hence, lower prices and reduced costs incurred by consumers to get useful information.
} 
against telemarketers. It varied from a few cents to USD 30.2. Tedeschi [18] showed that $82 \%$ online buyers were ready to provide access to their personal data to a new shopping mall in return for a chance to win 100 dollars. Spiekermann et al. [8] tested the willingness of respondents to give answers to personal questions in return for discounts or recommendations. Moreover, they verified if consumers were willing to pay for keeping their privacy - the percentage of such respondents amounted to $47 \%$.

However, most above-mentioned research concern the analysis of how the different WTA and WTP values developed for the same goods. Another research was carried out by Acquisti, John, and Loewenstein (http://www.heinz.cmu.edu/ acquisti/papers/acquisti-ISR-w orth.pdf), who compared the relationship between WTA and WTP in case of the same prices. Our research follows in their footsteps; however, it seems to us that we are introducing the explanations that shed more light on the phenomenon of differences between WTA and WTP. In their analysis, they formulated the following hypothesis:

The fraction of consumers who will reject an offer to obtain money in exchange for reduced privacy (WTA) is larger than the fraction of consumers who will accept an economically equivalent offer to pay money in exchange for increased privacy (WTP).

In our opinion, the above hypothesis defines the WTA phenomenon contrary to the theory and in the above-mentioned situation we face not WTA but rather 1-WTA. Therefore, in subsequent versions of their text the authors used another (revised) hypothesis:

The fraction of consumers who, faced with the option of obtaining money in exchange for reduced privacy (WTA), will reject it, is larger than the fraction of consumers who, faced with an economically equivalent option of paying for increased privacy (WTP), will accept it.

From the perspective of respecting privacy and aiming at data protection, two different situations can be analysed that will have the same effect:

1) the willingness to reject a proposal related to selling one's personal data to third parties, and

2) the willingness to withdraw from trading personal data that were disclosed before and the valuation of such an operation.

The first aspect is a situation where consumers do NOT agree on selling their data (they reject a proposal of buying their data), thus keeping their privacy. The latter case is the option where consumers are willing to actively buy back their data for a specified amount, to regain their privacy.

\section{REFERENCES to Similar PROBLEMS}

The situation (1) is an example related to the issue from the WTA area. In our context, we intend to determine what the willingness not to use the right to sell data is; in other words, what is the willingness to reject WTA. On the other hand, option (2) is the problem related to WTP. In our case, options (1) and (2) from the perspective of effects are equivalent personal data (privacy) will not be disclosed. The above-mentioned research indicated that with respect to the same goods people value WTA and WTP differently. We are interested in finding out if the same is true for the willingness to maintain / purchase privacy (which is understood as a zero-one choice), tested with the percentage of respondents selecting the option.

\section{HYPOTHESES}

It seems to us that consumers would be more ready to reject an offer to sell data than to accept an economically equivalent proposal to repurchase data they have shared before. In our opinion, personal data constitute goods that are sellable. As a result, consecutive actions, which are not known yet, may occur. Hence, we explain the 'willingness' to sell data. On the other hand, the data that have been shared before had to be related to specific ways of their use in the past. We expect that no situations occurred that according to consumers indicated their improper (hazardous) use and would necessitate incurring expenditures on 'buying back' data. As a result, the willingness to pay for the previously lost privacy would be low. Consequently, the research hypothesis will be as follows:

H1: Assuming that privacy is goods which consumers are ready to protect, the percentage of consumers who reject money offered for reduced privacy (reject WTA) [reject a proposal to sell and keep their data instead] is HIGHER than the percentage of consumers who accept an economically equivalent offer of paying in return for the enhanced privacy (WTP) [and will buy back or reserve their data]

\section{PROGRESS OF THE RESEARCH}

We will research the willingness to reject a proposal of selling data and the willingness to buy back data on two price levels - PLN 20.00 and PLN 60.00. We have assessed a decision situation in the reality of an online shop. We anchored the research on PLN 200.00, which constitutes the value of transactions closed in the shop. Depending on the tested option, you can sell your data, which in our decision making situation is related to:

- Getting a discount in the given amount (PLN 20.00 or PLN 60.00) for purchases of PLN 200.00, or

- The loss of a held discount resulting from sharing data in the past, amounting to PLN 20.00 or PLN 60.00 (i.e. increasing the cost of a one-off purchase by this amount).

Respondents were faced with two decision situations, which were described by us in the following manner:

\section{Situation A}

An online shop where you regularly spend about PLN 200.00/month on computer games and tickets to concerts offers you a promotional discount with another purchase in return for giving phone numbers and e-mail addresses of three of your friends or family members who might be interested in the offer of the shop. What will you do?

1) I will not share any information, whatever the value of discount.

2) I will give information in return for the discount of (a specific amount).

Situation A is an example where respondents are offered the sale of privacy of their relatives or friends for a quoted amount. A respondent may accept (and sell the goods, i.e. 
personal data, for an offered amount) or reject the proposal of sale and not to complete the transaction on such terms. Hence, a question may be asked if respondents are ready to accept a price and sell privacy or refuse to sell it.

Situation A presents the problem opposite to Willingness to Accept (WTA). From our point of view, we are interested in the percentage of respondents who do NOT agree to sell privacy (for the quoted price). Moreover, the percentage of those who (at this price) are willing to complete the transaction is the WTA percentage.

\section{Situation B}

While opening an account in an online shop where you presently spend about PLN 200 per month on computer games, you once gave active phone numbers and e-mail addresses of three members of your family and friends. As a consequence, you gained the right to receive a discount for every PLN 200.00 spent. The online shop has requested you to give consent to the use of such data for commercial and marketing purposes in the business of its subsidiary. If you do not give your consent, you will lose the discount. What will you do?

1) I give consent to the further use of data of my friends / relatives.

2) I give up the present discount (specified in an amount).

Situation B is an example where respondents are offered the purchase of privacy (reservation of privacy) of their relatives and friends for a specific amount. A respondent may agree (and in fact buy back the goods, i.e. personal data, for a quoted price) or reject the proposal to buy (i.e. give up the reservation option) and not to complete the transaction on such conditions. Therefore, we ask if they are willing to accept the quoted price to buy the privacy of their family members and friends or if they do not buy the data.

In situation $B$ we present directly the problem of Willingness to Pay (WTP). We are interested in what percentage of respondents are willing to buy (reserve) privacy for the quoted price. Moreover, the percentage of those who (at this price) are not willing to complete the transaction, is the opposite to WTP and will equal 1 minus WTP percentage.

According to $\mathrm{H} 1$, we expect that regardless of the price (with many different price levels), the percentage of those who reject the offer to sell their data will be higher than the percentage of respondents who are willing to buy back such data.

The results, even though based on declarative responses, have been reinforced with an incentive, which was to make the decision situation more realistic and thus display the characteristics of an experiment. All the respondents (students aged 19-25) were informed that the amount of PLN 100.00 would be distributed by lot among all the respondents. The amount might be increased or decreased depending on responses to the questions asked in the questionnaire. In other words, by checking the answer 'I give up my present discount' a respondent had to take into account the reduction of the prize money (the initial value was PLN 100.00) by the amount related to the rejected discount. The application of this method, in our opinion, contributed to the better analysis of questions and attracted closer attention from the respondents.
TABLE I: DeCISION SituATIONS AND WiLLINGNESSTo ProteCt PERSONAL DATA

\begin{tabular}{|c|c|c|c|c|}
\hline & Amount & Scope of data & $\begin{array}{l}\text { percentage } \\
1 \text {-WTA }\end{array}$ & $\begin{array}{l}\text { percentage } \\
\text { WTP }\end{array}$ \\
\hline \multirow[t]{2}{*}{$\begin{array}{l}\text { question } \\
1\end{array}$} & 20 PLN & $\begin{array}{l}\text { Phone numbers } \\
\text { and e-mail } \\
\text { addresses of } \\
\text { friends }\end{array}$ & $48 \%$ & $38.10 \%$ \\
\hline & 60 PLN & $\begin{array}{l}\text { Phone numbers } \\
\text { and e-mail } \\
\text { addresses of } \\
\text { friends }\end{array}$ & $37.14 \%$ & 26.83 \\
\hline $\begin{array}{l}\text { question } \\
2\end{array}$ & 50 PLN & $\begin{array}{l}\text { Address, age, } \\
\text { education, and the } \\
\text { number of } \\
\text { members in the } \\
\text { respondent's } \\
\text { household }\end{array}$ & $19.44 \%$ & $9.43 \%$ \\
\hline $\begin{array}{l}\text { question } \\
3\end{array}$ & 25 PLN & $\begin{array}{l}\text { Disclosing the } \\
\text { body weight of } \\
\text { the respondent }\end{array}$ & $20.75 \%$ & $12.04 \%$ \\
\hline $\begin{array}{l}\text { question } \\
4\end{array}$ & 50 PLN & $\begin{array}{l}\text { Information on } \\
\text { diseases suffered } \\
\text { by the respondent } \\
\text { (HIV infection, } \\
\text { hepatitis virus } \\
\text { infection, } \\
\text { venereal diseases) }\end{array}$ & $23.58 \%$ & $8.33 \%$ \\
\hline $\begin{array}{l}\text { question } \\
5\end{array}$ & 10 PLN & $\begin{array}{l}\text { Monitoring } \\
\text { visited places and } \\
\text { the respondent's } \\
\text { use of facilities } \\
\text { offered by aqua } \\
\text { park }\end{array}$ & $31.48 \%$ & $27.36 \%$ \\
\hline $\begin{array}{l}\text { question } \\
6\end{array}$ & 50 PLN & $\begin{array}{l}\text { Monitoring of } \\
\text { activity of a } \\
\text { respondent in the } \\
\text { Internet }\end{array}$ & $68.87 \%$ & $64.81 \%$ \\
\hline Channels & Group 1 & Group 2 & $\ldots$ & Group $c$ \\
\hline $\begin{array}{l}\text { Main } \\
\text { channel }\end{array}$ & $\begin{array}{l}\text { Channel } \\
1\end{array}$ & Channel 2 & $\ldots$ & Channel $c$ \\
\hline $\begin{array}{l}\text { Assistant } \\
\text { channel }\end{array}$ & $\begin{array}{l}\text { Channel } \\
2\end{array}$ & Channel 3 & $\ldots$ & Channel 1 \\
\hline
\end{tabular}

Source: own study

\section{ANALYSIS OF OUTCOME}

If the amount of the transaction was determined on a lower level (PLN 20.00), we received:

In Situation A the percentage of respondents rejecting the offer to sell their data amounted to $48 \%$.

In Situation B the percentage of those who were willing to buy back data totalled $38.10 \%$.

If the amount of the transaction was determined on a higher level (PLN 60.00), we received:

In Situation A the percentage of respondents rejecting the offer to sell their data amounted to $37.14 \%$.

In Situation B the percentage of those who were willing to buy back data totalled $26.83 \%$.

According to the results (the outcome is statistically insignificant):

$$
\begin{gathered}
(1-\mathrm{WTA} 20)=48 \%>\mathrm{WTP} 20=38.10 \%(p=0.4999) \\
(1-\mathrm{WTA} 60)=37.14 \%>\mathrm{WTP} 60=26.83 \%(p=0.3351)
\end{gathered}
$$


To verify the hypothesis from another angle, respondents were faced with other decision making situations (concerning different areas), based on the same schema; however, we researched exclusively the amount for selling / repurchasing personal data.

We obtained the following results:

$$
\begin{gathered}
\left(1-\mathrm{WTA}_{2}\right)=19.44 \%>\mathrm{WTP}_{2}=9.43 \%(p=0.0375) \text {-significant } \\
\left(1-\mathrm{WTA}_{3}\right)=20.75 \%>\mathrm{WTP}_{3}=12.04 \%(p=0.0850)
\end{gathered}
$$

$\left(1-\mathrm{WTA}_{4}\right)=23.58 \%>\mathrm{WTP}_{4}=8.33 \%(p=0.0023)$-significant

$$
\begin{aligned}
& \left(1-\mathrm{WTA}_{5}\right)=31.48 \%>\mathrm{WTP}_{5}=27.36 \%(p=0.5085) \\
& \left(1-\mathrm{WTA}_{6}\right)=68.87 \%>\mathrm{WTP}_{6}=64.81 \%(p=0.5283)
\end{aligned}
$$

The table below presents the amount of a transaction and the scope of data that are to be the subject of the transaction for each decision situation.

\section{CONCLUSIONS}

Regardless of a decision situation where a relative value of amount for which a transaction is to be completed or the scope of data subject to a transaction change, the results indicate that the willingness to protect information (measured as the percentage of respondents who do not decide to sell their data) is HIGHER than the economically equivalent and giving the same result (data protection) willingness to buy back data that were shared before.

The percentage in each group (avoiding sale vs. repurchasing) will certainly change depending on the amount and the scope of data (such differences will vary significantly); however, as we have expected, the percentage of those unwilling to sell will generally be higher than the percentage of those who declare their willingness to buy back. Therefore, with certain caution due to the incomplete representativeness of the group and the statistical significance of results, we accept $\mathrm{H} 1$ to be proven.

The described situation may result from the fact that people are characterised by their aversion to loss. Therefore, it is easier for us to turn down an offer of additional benefits (goods) than to spend money on the benefit (goods).

\section{REFERENCES}

[1] D. J. Solove, A Taxonomy of Privacy, University of Pennsylvania Law Review, pp. 477-564, 2006.

[2] L. D Brandeis, The Right to Privacy, Harvard Law Review, pp. 193-220, 1890.

[3] A. F Westin, Privacy and Freedom, Atheneum, New York, 1967.

[4] F. D. Schoeman, Privacy and Social Freedom, Cambridge university press, 1992.

[5] D. Kahneman, J. L. Knetsch, and R. H. Thaler, "Experimental tests of the endowment effect and the Coase theorem," Journal of Political Economy, pp. 1325-1348, 1990.

[6] W. S. Neilson, M. McKee, and R. P. Berrens, "Value and outcome uncertainty as explanations for the WTA vs WTP disparity," Handbook on Experimental Economics and the Environment, pp. 171-189, 2013.

[7] R. Thaler, "Toward a positive theory of consumer choice," Journal of Economic Behavior and Organization, vol. 1, no. 1, pp. 39-60, 1980.

[8] S. Spiekermann, J. Grossklags, and B. Berendt, "E-privacy In 2nd Generation ecommerce: Privacy preferences versus actual behavior," in Proc. the ACM Conference on Electronic Commerce, 2001, pp. 38-47.
[9] R. Chellapa and R. G. Sin, "Personalization versus privacy: An empirical examination of the online consumers' dilemma," Information Technology and Management, vol. 6, no. 2-3, pp. 181-202, 2005.

[10] L. Wathieu and A. Friedman, "An empirical approach to understanding privacy valuation," in Proc. the Fourth Workshop on the Economics of Information Security, Cambridge, MA, June 2-3, 2005.

[11] B. Huberman, E. Adar, and L. Fine, "Valuating privacy," in Proc. the Workshop on the Economics of Information Security, 2006.

[12] D. Cvrcek, M. Kumpost, V. Matyas, and G. Danezis, "A study on the value of location privacy," in Proc. Workshop on Privacy in the Electronic Society, 2006, pp. 109-118.

[13] K. L. Hui, H. H. Teo, and T. S. Y. Lee, "The value of privacy assurance: An exploratory field experiment," MIS Quarterly, vol. 31, no. 1, pp. 19-33, 2007.

[14] A. Acquisti and J. Grossklags, "Privacy and rationality in decision making," IEEE Security \& Privacy, pp. 24-30, January-February 2005

[15] H. R. Varian, F. Wallenberg, and G. Woroch, "The demographics of the do-not-call list," IEEE Security \& Privacy, vol. 3, no. 1, pp. 34-39. 2005.

[16] I. P. L. Png. (2007). On the value of privacy from telemarketing: Evidence from the 'Do Not Call' Registry. [Online]. Available: http://ssrn.com/abstract=1000533

[17] J. Tsai J, S. Egelman, L. F. Cranor, and A. Acquisti, "The effect of online privacy information on purchasing behavior: An experimental study," Information Systems Research, 2010.

[18] B. Tedeschi, "Everybody talks about online privacy, but few do anything about it," New York Times, p. 6, June 3, 2002.

Wojciech Bizon got the PhD in economics from University of Gdansk, Poland in 2006. Dr. Wojciech Bizon is currently vice dean of the Faculty of Economics, University of Gdansk, Poland and assistant professor in the Macroeconomics Chair. He is responsible for management of extra-mural studies system at the faculty, coordination of scientific and business cooperation of the faculty (with chambers of commerce, science \& technological parks, local authorities). He also carries out scientific research on the importance of knowledge transfer, innovations and entrepreneurship, as well as behavioral finance and macroeconomics. In the past has worked as vice president of consulting and training groups, and as a manager in companies representing the Polish financial sector.

Mr. Bizon is an expert on behavioral finance, entrepreneurship and the transfer of knowledge improving skills and innovation. He is a manager of postgraduate studies in the domain of entrepreneurship and economic education, was managing the international innovative project Case Simulator (development of modern training instruments to support entrepreneurship). In 2008 he was designated as a Polish national expert - a representative of the Ministry of Regional Development. Dr. Bizon is a member of the Executive Master of Business Administration in Banking Management Program Board, a member of the European Distance and E-learning Network as well as the Polish Academic E-learning Association. In 2007-2013 he was an expert of the Polish Ministry of Regional Development entrusted with the evaluation of applications for EU funds in the domain of information society.

Andrzej Poszewiecki got the $\mathrm{PhD}$ in economics from University of Gdansk, Poland in 2009. He is Assistant Professor (adiunkt) at the Department of Macroeconomics, Faculty of Economics, University of Gdańsk, Member of the American Economic Association, Member of the Vice-Chancellor Team for Sea Policy Implementation, Member of the Scientific Council of the Pomeranian Park of Science and Technology in Gdynia, Member of the Regional Thematic Network for Pomorskie Voivodeship, and Member of the Board of the National Foundation for the Culture of Entrepreneurship. Three-times winner of the University Vice-Chancellor Prize for scientific achievements (2008, 2011, and 2014).

$\mathrm{Mr}$ Poszewiecki is a participant of numerous scientific projects (domestic and international), including regional cooperation network in the area of the baltic sea (based on the hierarchical analysis of concentrations), role of innovation in the development of peripheral regions, analysis based on the example of countries of the baltic sea area, Baltic Sea Virtual Campus - Transregional Management (BSVC), Agora - Network Sustainable Tourism Development in The Baltic Sea Region, and AGORA 2.0 Heritage Tourism for Increased Baltic Sea Region Identity. At present, he is the manager of the NCN project entitled 'Economic Analysis of the Concept of Privacy'. 